\title{
Expression of CD44 molecules and CD44 ligands during human thymic fetal development: expression of CD44 isoforms is developmentally regulated
}

\author{
Dhavalkumar D. Patel, Laura P. Hale1, Leona P. Whichard, Gilbert Radcliff, \\ Charles R. Mackay ${ }^{2}$ and Barton F. Haynes \\ Department of Medicine, Division of Rheumatology, Allergy and Clinical Immunology, Department of \\ Immunology, and Duke Universıty Arthritıs Center, Duke University Medical Center, Durham, NC 27710 , \\ USA \\ ${ }^{1}$ Department of Pathology, Duke University Medical Center, Durham, NC 27710, USA \\ 2Basel Institute for Immunology, Basel, Switzerland
}

Key words: CD44, differentiation, fibronectin, hyaluronan, thymus

\begin{abstract}
It has recently been recognized that CD44 comprises a large family of alternatively spliced forms. In the thymus, CD44 has been postulated to play an important role In immature $\mathrm{T}$ cell migration and maturation. In this paper, we have studied the expression of CD44 molecules and two CD44 ligands, hyaluronan (HA) and fibronectln (FN), during human thymic fetal development. We found that mAbs against all CD44 lsoforms (A3D8 or A1G3) reacted with both thymic epithelial (TE) cells and thymocytes beginning at the time of initial colonization of the human thymus by hematopoietic stem cells at 8.2 weeks of fetal gestation. However, mAbs specific for spllce varlents of CD44 containlng membrane-proximal inserts $(11.24,11.10$ and 11.9$)$ reacted only with terminally differentlated TE cells in and around Hassall's bodles beginning at 16-19 weeks of fetal gestation. Studies of differentlated versus undifferentlated TE cells in vitro confirmed the selective expression of CD44 varlant isoforms on terminally differentlated TE cells. Expression of HA and FN was determined by fluorescence microscopy using either blotinylated-HA binding protein or an antl-FN mAb. We found that whereas FN was present throughout the human fetal thymus beginning at 8.2 weeks, HA was not present untll 16 weeks of gestational age. These data demonstrate the differential expression of standard versus variant CD44 isoforms during thymic ontogeny and Implicate CD44 interactions with ligands other than HA as important in the earlier stages of human thymus development.
\end{abstract}

\section{Introduction}

The CD44 family of glycoproteins is comprised of multiple alternatively-spliced isoforms that are expressed on a wide variety of cell types including hematopoietic and epithelial cells (reviewed in 1,2). Hematopoietic cells predominantly express the most common, or standard, 85-95 kDa form of CD44 (CD44S) encoded by exons 1-5, 15-17 and 19 (Fig. 1). In addition to CD44S, epithelial and some hematopoietic cells may also express variant isoforms of CD44 (CD44v) via alternative splicing of at least nine exons (v2-v10) in humans (3) and 10 exons $(\vee 1-\vee 10)$ in rodents (2).
CD44 molecules have been postulated to be involved in a variety of processes including lymphocyte homing, cell migration, cell-cell and cell-substrate interactions, lymphopoiesis, and $T$ cell activation (reviewed in 4-6). In both humans and rodents, expression of variant isoforms of CD44 containing $v 6$ has been associated with a metastatic phenotype of epithelial cell malignancies (7-12).

In the thymus, CD44 expression has been implicated in mediating homing of T cell precursors to the thymus (reviewed in 4,6) and CD44 molecules are more highly expressed on

Correspondence to: D. D. Patel, 218 CARL Building, Box 3258, Duke University Medical Center, Durham, NC 27710, USA 


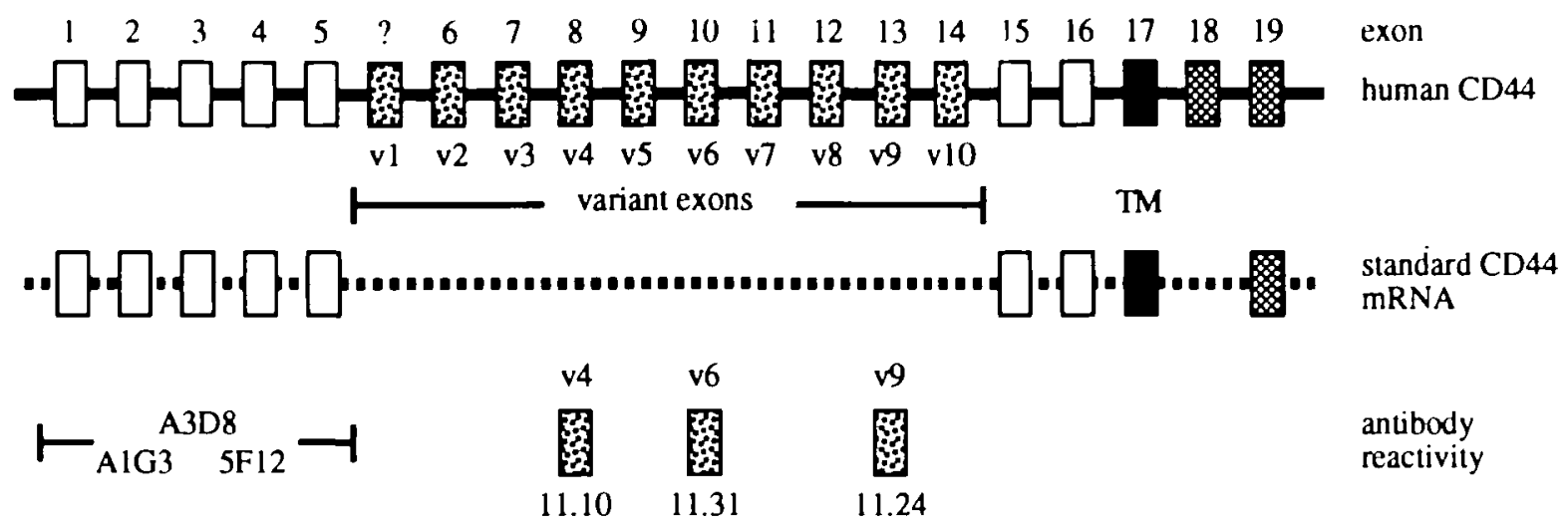

Fig. 1. CD44 genomic structure and reactivity of antibodies to CD44. A schematic representation of the genomic structure of the human CD44 gene, as described by Screaton et al. (3), is shown at the top. The extracellular portion of standard forms of CD44 is depicted by open rectangles, the intracellular portion by cross-hatched rectangles and the exon encoding the transmembrane (TM) regron is depicted by a filled rectangle. The human CD44 gene exons (exons 6-14 or v2-v10) that can be alternatively spliced into the mRNA to form higher molecular weight variant isoforms of CD44 are depicted by stippled rectangles. Rodent CD44 genes contain an additional variant exon ( $v 1$ ), indicated by a stippled rectangle with a question mark, between human CD44 exons 5 and 6 (2). A depiction of mRNA encoding the most common form of CD44 is shown. Standard forms of CD44 may have short (exon 18) or long (exon 19) cytoplasmic domains Reactivities of the CD44 antibodies used in this study are shown at the bottom. mAbs A3D8, A1G3 and 5 F12 react with conformational epitopes in the extracellular portion of standard CD44 (19). Antibodies $11.10,11.31$ and 11.24 react with portions of CD44 encoded by exons v4, v6 and v9 respectively (16).

medullary versus cortical thymocytes $(13,14)$. Variant isoforms of CD44 are transiently expressed on stimulated peripheral blood $B$ cells, $T$ cells and constitutively expressed on monocytes/macrophages $(15,16)$.

Mackay et al. have demonstrated expression of CD44 varıant isoforms containing $v 4, v 6$ and $v 9$ inserts in Hassall's bodies (HB) in post-natal thymus (16). In this study, we have examined the expression of CD44 isoforms and two CD44 ligands, hyaluronan (HA) and fibronectin (FN), throughout human fetal thymic development.

\section{Methods}

\section{Antibodies}

The following mAbs were used: A3D8, A1G3 and 5F12 (all isoforms of CD44) (17-19); 11.10 (CD44 isoforms containing exon v4) (16); 11.31 (CD44 isoforms containing exon v6) (16); 11.24 (CD44 isoforms containing exon v9) (16); $A E-1, A E-2$ and $A E-3$ (anti-keratins, from T. T. Sun, NYU, New York) (20); TE4 [medullary thymic epithelial (TE) cells] (21); TE7 (thymic stroma and fibroblasts) (21); TE19 (HB) (22); STE1 (HB) (D D. Patel et al., unpublished); LeuM3 (monocytes) (23); 3A1e (pan T cell marker CD7) (24); 1810 (fibroblasts) (25); FN15 (FN) (Sigma, St Louis, MO); and P3 × 63/Ag8(P3) (IgG1 control mAb) (ATCC, Rockville, MD). mAb 11.24 has been shown to be specific for exon v9 containing isoforms of CD44 by peptide binding studies (16). To confirm that mAb 11.24 did not cross-react with other cell surface proteins and was specific for CD44v9, we tested the ability of mAb 11.24 to react with Jurkat cells that did not express any form of CD44 (Jurkat parent), Jurkat cells that expressed the standard form of CD44 with no variant exons (Jurkat/CD44S) and Jurkat cells that expressed a form of CD44 containing exons v8v10 (Jurkat/CD44v8-10) (19). mAb 11.24 reacted only with Jurkat cells that expressed the isoform of CD44 containing exons $v 8-v 10$, further demonstrating the specificity of $m A b$ 11.24 for exon v9 of CD44 (not shown).

\section{Indirect immunofluorescence of human thymic tissues}

Post-natal thymic tissues, taken as a necessary part of surgical procedures, were obtained from children undergoing corrective cardiovascular surgery as discarded tissue from the Department of Pathology, Duke University Medical Center. Fetal tissues were obtained as discarded tissue from the Department of Pathology, Duke University Medical Center, from etther elective first trimester abortions or at the time of surgery for ectopic pregnancy. Gestational age was determined by crown-rump length, menstrual records and fetal part morphology. Frozen tissue specimens were embedded in OCT compound, cut into $4 \mu \mathrm{m}$ sections and fixed in acetone for $5 \mathrm{~min}$ at $-70^{\circ} \mathrm{C}$. mAbs were used in indirect immunofluorescence assays with fluorescein-conjugated goat anti-mouse IgG (GAM-FITC) (Kirkegaard \& Perry, Gaithersburg, MD) as described (26). Biotinylated HA binding protein (HABP) (Pel-Freez, Rogers, AK) (27) was also used in indirect immunofluorescence assays with fluorescein-conjugated streptavidin (Southern Biotechnology Associates, Birmingham, $A L$ ). The specificty of HABP binding to tissues was determined by inhibition of HABP-biotin binding to thymus tissues with HA (Sigma). We found that binding of $0.1 \mu \mathrm{g}$ of HABP-biotin to fetal skin and to fetal and post-natal thymus was completely inhibited by $12.5 \mu \mathrm{g}$ of unlabeled HA (not shown)

\section{Cell culture conditions}

TE cells were cultured by an explant technique and propagated in enriched medium (containing epidermal growth factor and insulin) on mitomycin C-treated $3 \mathrm{~T} 3$ fibroblast feeder layers as previously described (28). Thymic fibroblasts were removed by treatment with $0.02 \%$ EDTA in PBS followed by 
Table 1. Expression of CD44 molecules in human fetal and postnatal thymus

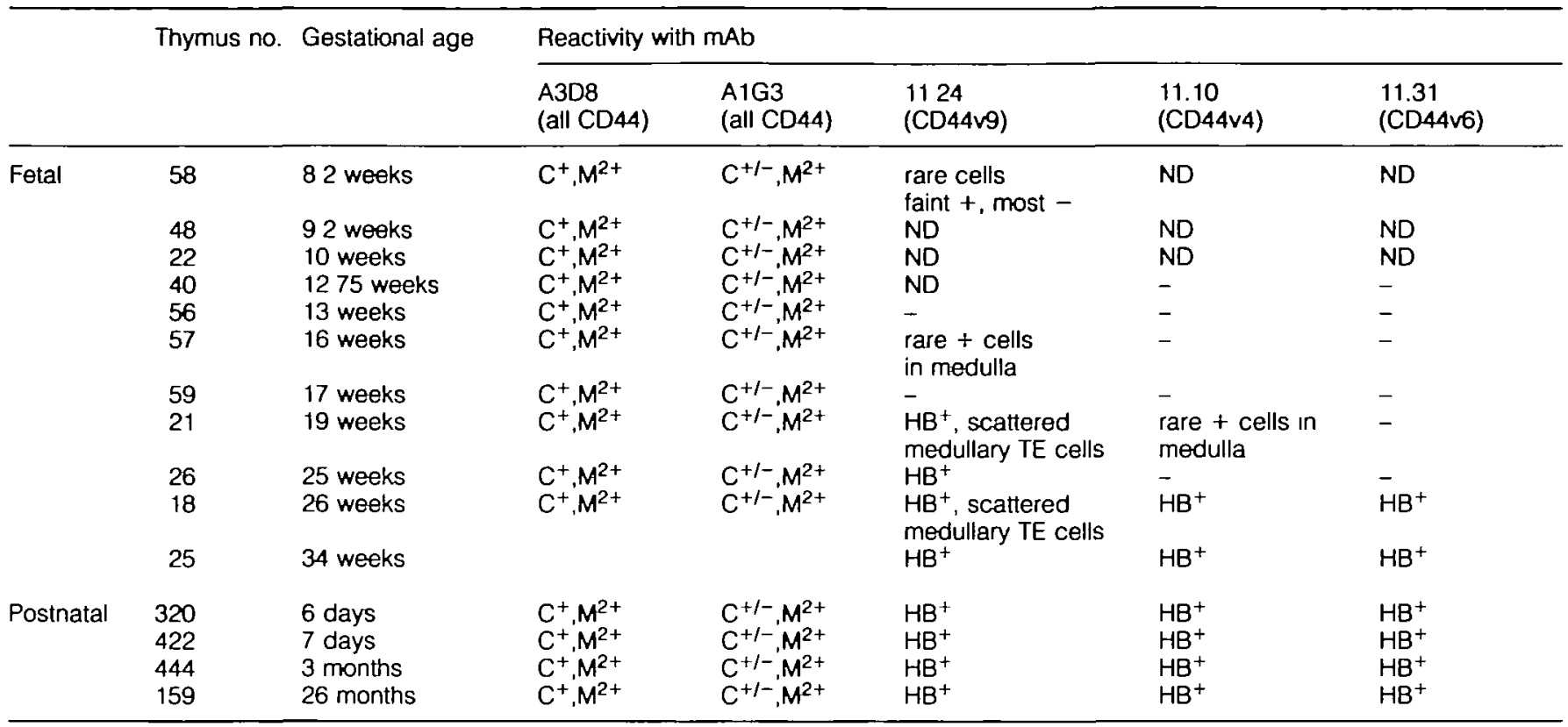

$\mathrm{HB}=$ Hassall's bodies; $\mathrm{C}=$ cortex; $M=$ medulla; $+=$ all cells positive; $2+=$ a degree of brightness greater than,$++1-=\mathrm{a}$ subset bright positive; $-=$ all cells negative; $\mathrm{ND}=$ not done.

complement-mediated lysis with anti-fibroblast MAb 1B10 (25). ЗТ 3 fibroblast feeder layers were removed by treatment with $0.02 \%$ EDTA in PBS prior to detachment of TE cells from culture dishes with $0.05 \%$ trypsin in PBS containing $0.02 \%$ EDTA. TE cell preparations were $>95 \%$ positive for the keratin markers $A E-1$ and $A E-3,0-5 \%$ positive for the fibroblast marker TE7, and negative for the macrophage marker LeuM3 and thymocyte marker CD7. Cultured TE cells were allowed to spontaneously differentiate in vitro over time (3-12 weeks) to squamous forms with a large flattened cellular morphology (29) or were induced to differentiate with the addition of varying amounts of retinoic acid (Sigma) to DME (Gibco, Grand Island, NY) containing 5\% FCS without growth factors. Terminally differentiated TE cells had a characteristic squamous cell morphology, and were positive for markers of differentiated TE cells including TE19 (22), STE1 and STE2 (D. D. Patel et al., unpublished data).

Thymocytes were obtained by separation from thymus tissue and purified by density gradient centrifugation as described (30). Thymocytes were used immediately or frozen in media containing $20 \%$ FCS, $7.5 \%$ dimethylsulfoxide and $10 \mu \mathrm{g} / \mathrm{ml}$ gentamicin (BioWhittaker, Walkersville, MD) in RPM! 1640 until use (30). Thymocytes were cultured in growth media containing $15 \%$ human $A$ serum and $10 \mu \mathrm{g} / \mathrm{ml}$ gentamicin in RPMl 1640 at a density of $2 \times 10^{6} \mathrm{cells} / \mathrm{ml}$. Thymocytes were activated with $5 \mathrm{U} / \mathrm{ml}$ rlL-2 (Cetus, Emeryville, CA) and either $2 \mu \mathrm{g} / \mathrm{ml}$ phytohemagglutinin (PHA; Sigma) or $100 \mu \mathrm{g} / \mathrm{ml}$ concanavalin $A$ (Con $A_{i}$ Sigma) in growth media for $96 \mathrm{~h}$ and washed with $0.3 \mathrm{M}$ methyl $\alpha$-D-mannopyranoside ( $\alpha \mathrm{MM}$; Sigma) prior to analysıs (18).

Peripherat blood mononuclear cells (PBMC) were purified (30) and cultured in media containing $15 \%$ human A serum and $10 \mu \mathrm{g} / \mathrm{ml}$ gentamicin in RPMI 1640. PBMC were activated with $0.5 \mu \mathrm{g} / \mathrm{ml}$ PHA or $10 \mu \mathrm{g} / \mathrm{ml} \mathrm{Con} \mathrm{A} \mathrm{(18)} \mathrm{and} \mathrm{washed} \mathrm{with}$ $0.3 \mathrm{M} \alpha \mathrm{MM}$ in RPMI 1640 prior to analysis

\section{Detection of cell surface antigens}

Unfixed cultured cells were suspended in PBS containing 2\% BSA and $0.1 \% \mathrm{NaN}_{3}$, stained by indirect immunofluorescence, and analyzed on a FACStar Plus (Becton Dickinson, Mountain View, CA). Data was further processed using the software program PC Lysys (Becton Dickinson).

\section{Detection of antigens immobilized on nitrocellulose}

Cells were harvested as described above and lysed, or lysed in situ without trypsin treatment, in a buffer containing PBS, $2 \%$ NP-40, $1 \mathrm{mM}$ phenylmethylsulfonyl fluoride and $0.1 \mathrm{mM}$ tosyl-t-lysyl chloromethylketone. A soluble protein extract was prepared by centrifugation $(10,000 \mathrm{~g})$ for $30 \mathrm{~min}$ at $4^{\circ} \mathrm{C}$. Proteins were separated by polyacrylamide gel electrophoresis and electrophoretically transferred to nitrocellulose filters. Antigens on nitrocellulose filters were detected by indirect immunoperoxidase staining using horseradish peroxidaseconjugated goat anti-mouse IgG antibodies (Promega, Madison, WI). Protein bands were visualızed by incubation with Rennaisance ${ }^{T M}$ chemiluminescence reagent (DuPont NEN, Boston, MA) followed by exposure to autoradiography film.

\section{Results}

CD44 expression in human fetal thymus throughout thymic ontogeny

The expression of CD44 isoforms in human thymus was initially determined by testing frozen sections of human thymus 

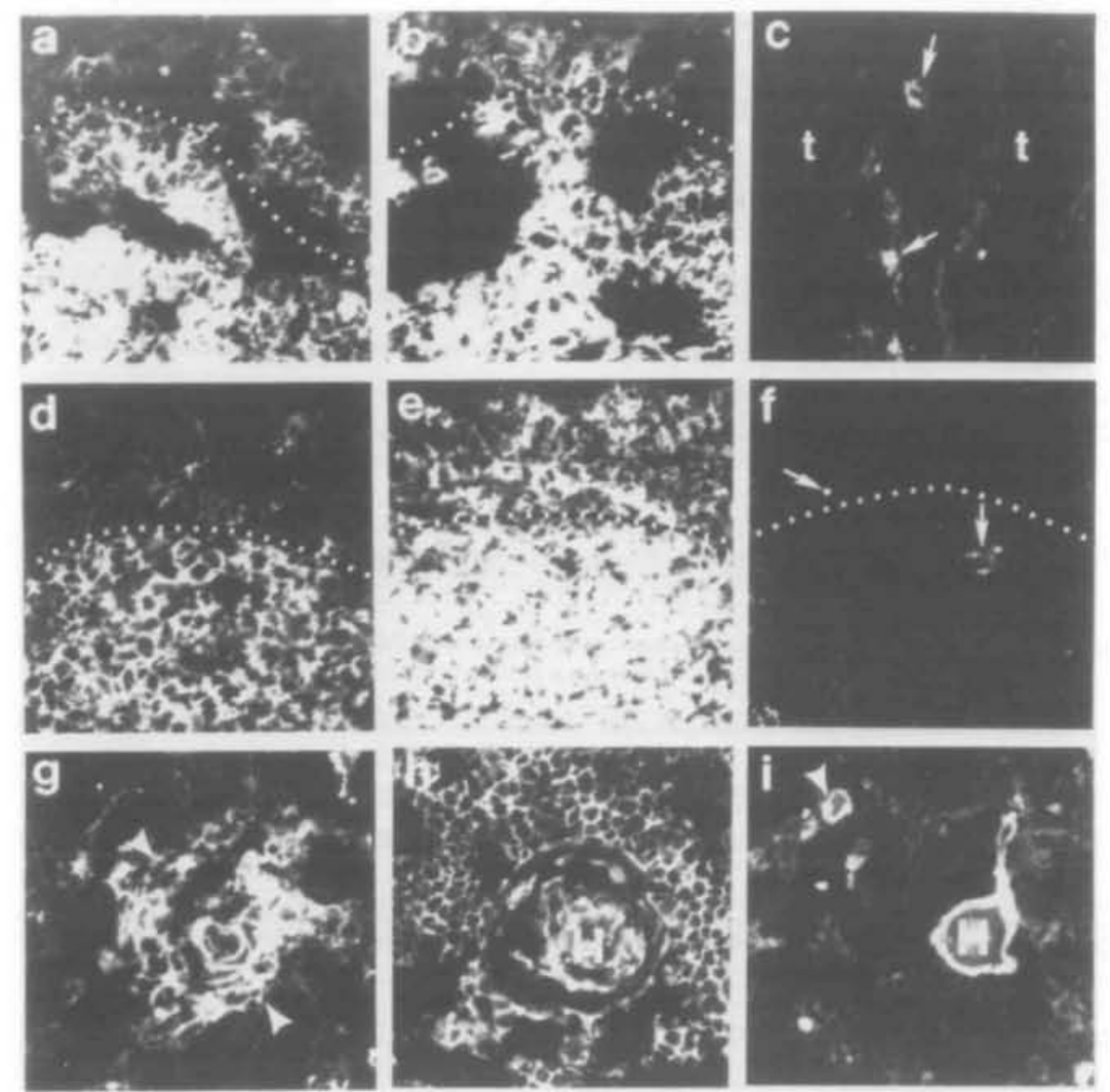

Fig. 2. Ontogeny of expression of CD44 molecules in human fetal thymus. Panels (a)-(c) show fetal thymus no. 58 from 8.2 weeks of gestation just at the time of colonization of the thymus rudiment by hematopoietic stem cells. Panel (a) shows reactivity of mAb A1G3, panel (b) shows reactivity of $\mathrm{mAb} A 3 D 8$ and panel (c) shows reactivity of mAb 11.24. Panels (a) and (b) show that A1G3 and A3D8 react more strongly with central portions of the thymus (below the dotted lines) and weakly with the outer portions of the thymıc rudiment above the dotted lines. The large dark areas separating portions of the thymus are artifact from snap-freezing the tissue. In panel (c), the thymus areas (t) of the right thymus of tissue no. 58 are negative for 11.24 . There were only scattered $11.24^{+}$cells in an interlobular septae in the left thymus of tissue no. 58. Panels $(d)-(f)$ show sequential sections from the same area of fetal thymus no. 56 from 13 weeks of fetal gestation. Medullary areas are below the dotted lines and cortical areas above the dotted lines. Panel (d) shows reactivity with antibady A1G3, panel (e) shows reactivity with mAb A3D8 and panel $(f)$ shows reactivity with mAb 11.24. Whereas A1G3 and A3D8 reacted well with fetal thymus no. 56,1124 did not react. The arrows in panel $(\mathrm{f})$ show autofluorescent areas. mAb 11.24 reacted strongly with $\mathrm{HB}$ and TE cells around HB beginning at $\sim 19$ weeks of gestation. Panel $(\mathrm{g})$ shows reactivity of mAb 11.24 with fetal thymus no. 18 from 26 weeks of gestation, while panels (h) and (i) show reactivity of fetal thymus no. 25 from 34 weeks of gestation with antibody A3D8 in panel (h) and 1124 in panel (i). Cells around early HB are shown in panel $(\mathrm{g})$ between the arrowheads, while $\mathrm{H}$ points out $\mathrm{HB}$ in panels ( $\mathrm{h}$ ) and (i). An arrowhead also shows a smaller HB in panel (i). All panels were photographed at a magnification of $\times 400$.

for reactivity with mAbs to all forms of CD44 (A3D8, A1G3), and mAbs 11.24, 11.10, 11.31 to isoforms containing CD44v9, CD44v6 and CD44v4 respectively (16). Fetal thymus tissues ranging from the time of initial colonization of fetal thymus by hematopoietic stem cell precursors ( 8.2 weeks of gestation) to 34 weeks of gestational age were tested (Table 1). Whereas mAbs A3D8 and A1G3, that react with two distinct epitopes on all CD44 isoforms, reacted with TE cells, fibroblasts and thymocytes of all fetal thymuses tested, mAb 11.24 did not react with TE cells or thymocytes in 8.2 (no. 58), 13 (no. 56) or 17 (no. 59) week thymus (Fig. 2). Rare 11.24 reactive medullary TE cells were present in thymus no. 57 (16 weeks gestational age). Thymuses 19 weeks of gestational age and older contained swirls of terminally differentiated TE cells (HB) and $\mathrm{mAb} 11.24$ reacted with fetal thymuses $\geqslant 19$ weeks of age in a HB-specific pattern (Fig. 2). mAbs against other
CD44 variant isoforms containing v4 (11.10) and v6 (11.31) inserts reacted with rare $\mathrm{HB}$ in fetal thymus no. 21 (19 week), did not react with thymus no. 26 (25 week) HB, and reacted with fetal thymus 18 (26 week) and 25 ( 34 week) as well as with post-natal thymus in a HB-specific manner. Thus, these data suggested that expression of CD44 variant isoforms containing exon 13 (variant exon 9), exon 10 (variant exon 6) and exon 8 (variant exon 4) are hallmarks of terminally differentiated TE cells. As previously reported (21), in postnatal human thymus, anti-CD44 mAbs A3D8 and A1G3 reacted brightly with $T E$ cells, and with medullary and cortical thymocytes (not shown). In addition, mAbs A3D8 and A1G3 also reacted with thymic macrophages containing lipofuscin pigment, with thymic vessels, and with thymic fibroblasts in interlobular septae and the thymic capsule. In contrast, in post-natal thymus the pattern of reactivities of mAbs 1124 , 


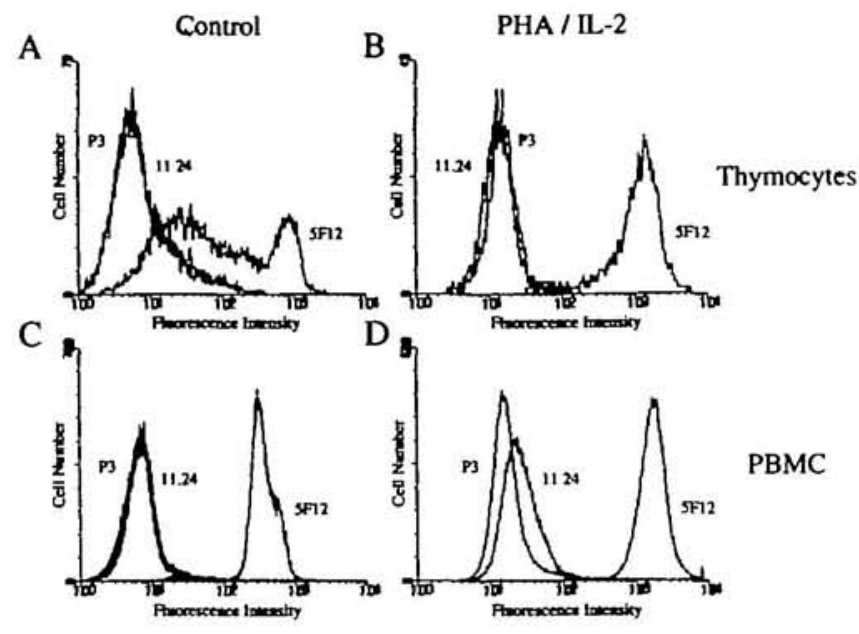

Flg. 3. Expression of CD44 isoforms on human thymocytes and PBMC Freshly isolated thymocytes (A), PHAVIL-2 activated thymocytes (B), PBMC (C) and PHAVIL-2 activated PBMC (D) were incubated with mAb 5F12 or 11.24 . Cells were analyzed by indirect immunofluorescence and flow cytometry and their histograms are shown. The profile of control lgG P3 $\times 63 / \mathrm{Ag} 8$ preparation (P3) is also shown in each panel. Data are representative of three experiments

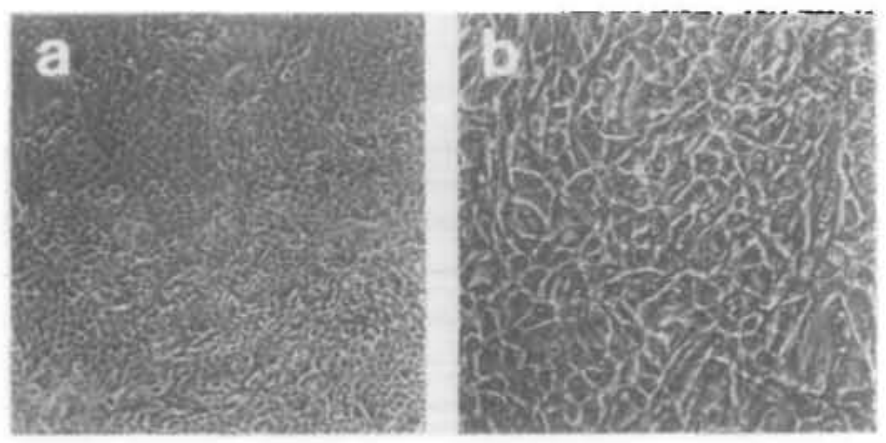

Flg. 4. Photomicrographs of TE cells at different stages of differentiation. Shown are photomicrographs of TE cells that were rapidly proliferating $(A)$ and TE cells that were termınally differentiated (B). Note that the proliferating, undifferentiated TE cells are small and that the terminally differentiated TE cells are large Data are representative of three experiments. $(\times 100)$

11.31 and 11.10 was identical to their reactivity with 34 week fetal thymus (no. 25), with reactivities to HB, TE cells around $\mathrm{HB}$ and with pigment-containing cells that likely were macrophages.

\section{Expression of CD44v9, v4 and v6 on activated thymocytes and PBMC}

In indirect immunofluorescence assays and flow cytometry analysis, neither unstimulated thymocytes nor PBMC reacted with $\mathrm{mAb} 11.24$ (Fig. $3 \mathrm{~A}$ and $\mathrm{C}$ ). To determine if CD44v9 expression in thymus was limited to TE cells, we tested the ability of PHA and Con A to induce CD44v9 expression in thymocytes and PBMC. PHA has been shown to induce CD44v6 and CD44v9 expression in human PBMC (16), and to induce CD44v6 in rat T cells (15). PBMC, when activated

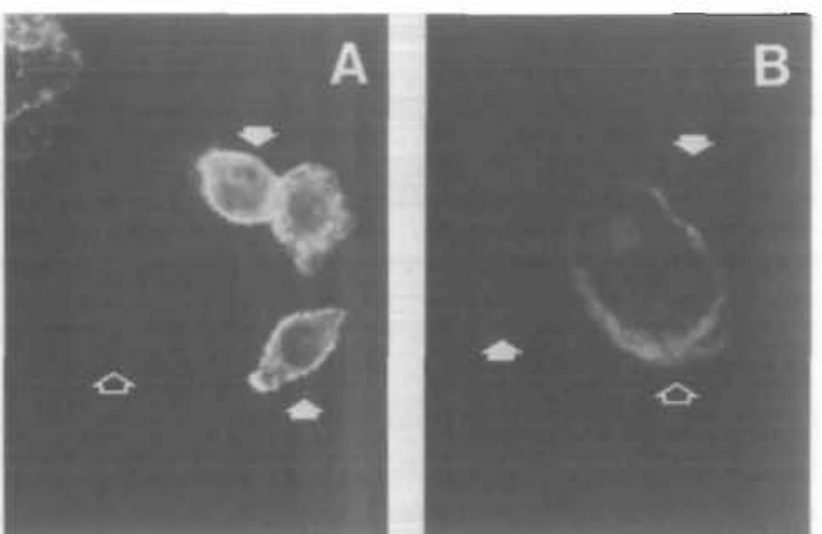

Fig. 5. Variant Isoforms of CD44 containing exon v9 are expressed selectively on terminally differentiated TE cells. TE cells from primary cultures that contained morphologically and phenotypically terminally differentiated cells were assayed by indirect immunofluorescence for reactivity with $\mathrm{A} 3 \mathrm{D} 8 \mathrm{~A}(\mathrm{~A})$ and $11.24(\mathrm{~B})$ The smaller proliferating TE cells (indicated by filled arrows) were high expressers of CD44 but were negative for isoforms containıng exon $v 9$. The larger terminally differentiated TE cells (Indicated by open arrows) were low expressers of total CD44 and positive for isoforms contanning exon v9 Data are representative of six experiments. $(\times 400$.)

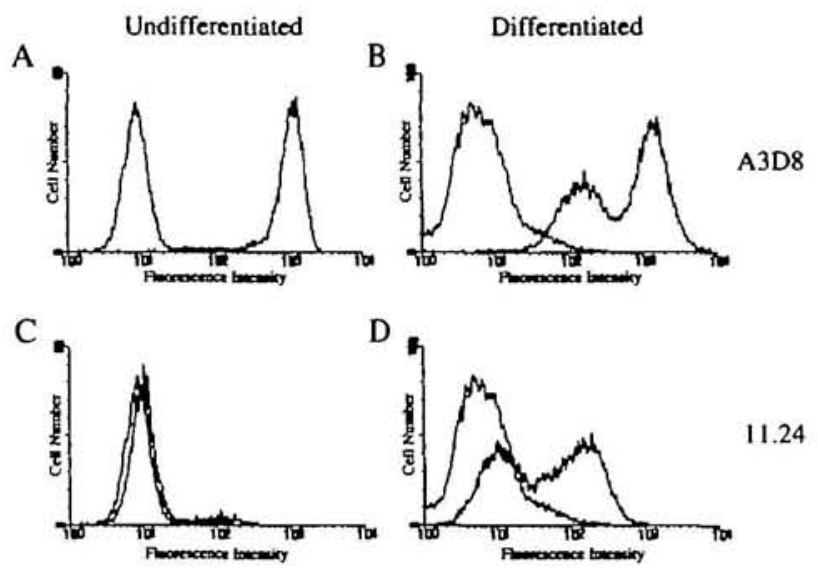

Flg. 6. Cell surface reactivity of CD44 mAbs to cultured TE cells. The pattern of reactivity of mAbs to all forms of CD44 (A3D8) and variant isoforms containing exon v9 (11.24) on cultured TE cells that displayed a morphology of proliferating ( $A$ and $C$ ) or terminally differentiated (B and D) cells is shown. TE cells with a morphology of actively proliferatıng cells expressed high levels of CD44 but did not express variant isoforms containing exon v9. TE cell cultures with a predomınantly terminally differentiated cell morphology had two subsets of cells based on the expression of CD44 isolorms. Based upon analysis of forward scatter versus fluorescence, the larger differentiated cells expressed low levels of total CD44 and low levels of CD44v9; the smaller undifferentiated cells expressed high levels of total CD44 and no CD44 9 . Data are representative of 12 experiments.

with either PHA or Con A, could be induced to express CD44v9 (Fig. 3D) but not v4 or v6 (data not shown), as detected by indirect immunofluorescence with mAbs 11.24, 11.10 and 11.31 respectively, and flow cytometry. Neither unstimulated thymocytes nor thymocytes activated with either PHAVIL-2 or Con AVIL-2 for 4 days expressed detectable levels 

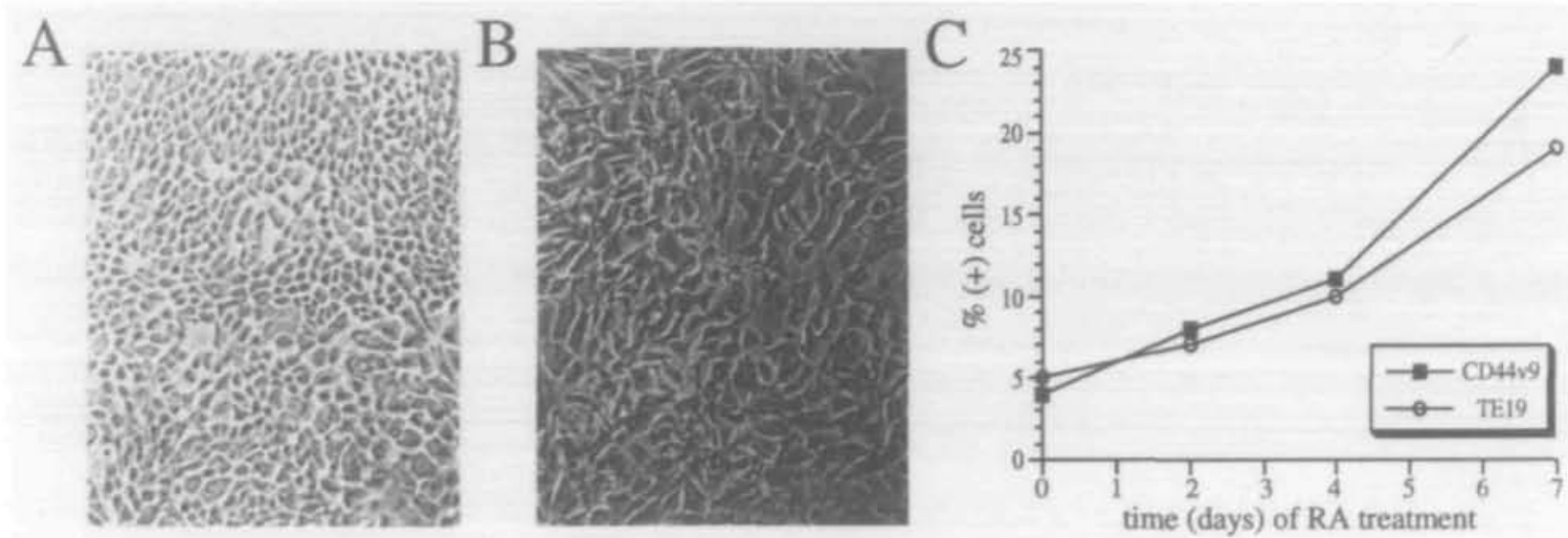

Flg. 7. RA induces differentiation of TE cells and up-regulation of variant isoforms of CD44. The morphology of control TE cells and TE cells treated for $96 \mathrm{~h}$ with $10^{-6} \mathrm{M}$ RA are shown in panels $(\mathrm{A})$ and $(\mathrm{B})$ respectively $(\times 100)$. The RA-treated cells were larger and were morphologically similar to terminally differentiated TE cells. RA-treated cells were also phenotypically more differentiated than control as they reacted with TE 19 mAb. Panel (C) shows a representative of a time course of RA treatment of TE cells. TE cells were cultured in enriched media contaınıng $10^{-6} \mathrm{M}$ RA for $0-7$ days and their differentiation status was determined by phenotypic analysis Shown is the percentage of $1124^{+}$and TE19 ${ }^{+}$ cells in TE cell cultures stımulated for $0-7$ days with RA. Data are representative of three experiments.

of CD44v9 (Fig. 3B), v4 or v6 (data not shown) on their surface. In a separate experiment using thymocytes from three different individuals, only $2 \pm 2 \%$ of thymocytes stimulated for 4 days with PHA/IL-2 and $5 \pm 1 \%$ of thymocytes stimulated for 7 days with PHA/IL-2 expressed detectable levels of CD44V9; no CD44v4 or v6 expression was detected on thymocytes at either 4 or 7 days of stimulation with PHAIIL-2. Thus, CD44V9, $\checkmark 4$ and $v 6$ reactivity in thymus was limited primarily to TE cells and in the case of CD44v9, also to scattered pigmentcontaining macrophages.

\section{Expression of CD44 isoforms on cultured TE cells}

To confirm the notion that terminally differentiated TE cells expressed CD44 variant isoforms, further studies were performed on cultured TE cells using the CD44V9 mAb, 11.24. TE cells spontaneously differentiate in vitro in culture from small proliferating cells (Fig. $4 \mathrm{~A}$ ) to larger non-proliferating terminally differentiated cells $(24,29)$ (Fig. 4B). Large TE cells were found to be phenotypically differentiated as they were reactive with mAbs TE19 (31) and STE1 (D. D. Patel and B. F. Haynes, unpublished), markers of terminally differentiated TE cells. In TE cell cultures containing spontaneously differentiated TE cells, cells with a morphology of small undifferentiated cells reacted with anti-CD44 mAb A3D8 brightly (Fig. 5A) but did not react with mAb 11.24 (Fig. 5B). $T E$ cells with a large terminally differentiated (squamous) morphology reacted with mAb A3D8 dimly (Fig. 5A) and were strongly reactive with mAb 11.24 (Fig. 5B).

These data also suggested that expression of total CD44 in the large differentiated TE cells was lower than that in the small proliferating TE cells. To test this hypothesis, TE cells from cultures that were either undifferentiated or well differentiated were further analyzed by indirect immunofluorescence assays and flow cytometry comparing reactivity with mAbs A3D8 and 11.24 (Fig. 6). TE cells from undifferentiated TE cultures expressed high levels ( 2 logs mean fluorescence channel above background) of total surface CD44 as determined by reactivity with mAb A3D8 (Fig. 6A) and did not

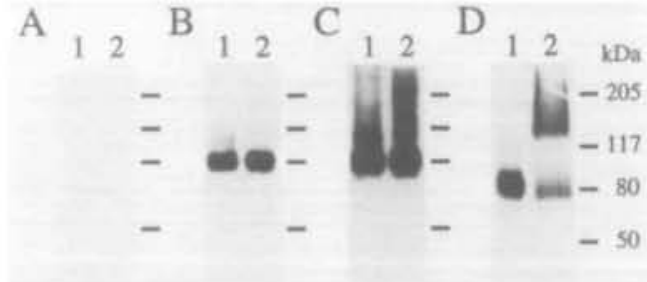

Fig. 8. Detection of CD44 proteins immobilized on nitrocellulose filters. Protein extracts from thymocytes and TE cells at different stages of differentiation were separated by discontinuous polyacrylamide gel electrophoresis, transferred to nitrocellulose and reacted with mAb A3D8 or control mAb (P3) mAbs were visualized by indirect immunoperoxidase and chemiluminescence. Panel (A) shows the reactivity of control mAb p3 with (1) thymocytes and (2) thymic epithelial cells. Panel (B) shows the reactivity of mAb A3D8 with (1) thymocytes and (2) TE cells from a culture containing $90 \%$ undifferentiated TE cells. Panel (C) represents an overexposure of panel (B) to show the high molecular weight isoforms of CD44 which are present in low abundance. Panel (D) shows the reactivity of mAb A3D8 with (1) thymocytes and (2) TE cells from a culture containing $>95 \%$ terminally differentiated TE cells. Data are representative of three experiments.

express surface CD44v9 detectable by mAb 11.24 (Fig. 6C). TE cells from differentiated TE cultures contained two populations of cells based on expression of total CD44 (Fig. 6B) and CD44v9 (Fig. 6D), one that expressed high levels of CD44 and no CD44v9, and the other that expressed lower levels of CD44 and low levels of CD44v9. As determined by analysis of fluorescence versus forward scatter, the small cells expressed high levels of surface CD44 but did not react with MAb 11.24. and the large cells expressed low levels of both surface CD44 and CD44v9 (not shown). Thus, these data confirm that while total CD44 expression decreased with terminal differentiation of TE cells, expression of CD44v9 increased.

Retinoic acid-induced differentiation of TE cells

To further test the hypothesis that CD44v9 expression on TE cells was limited to differentiated cells, we treated TE cells 

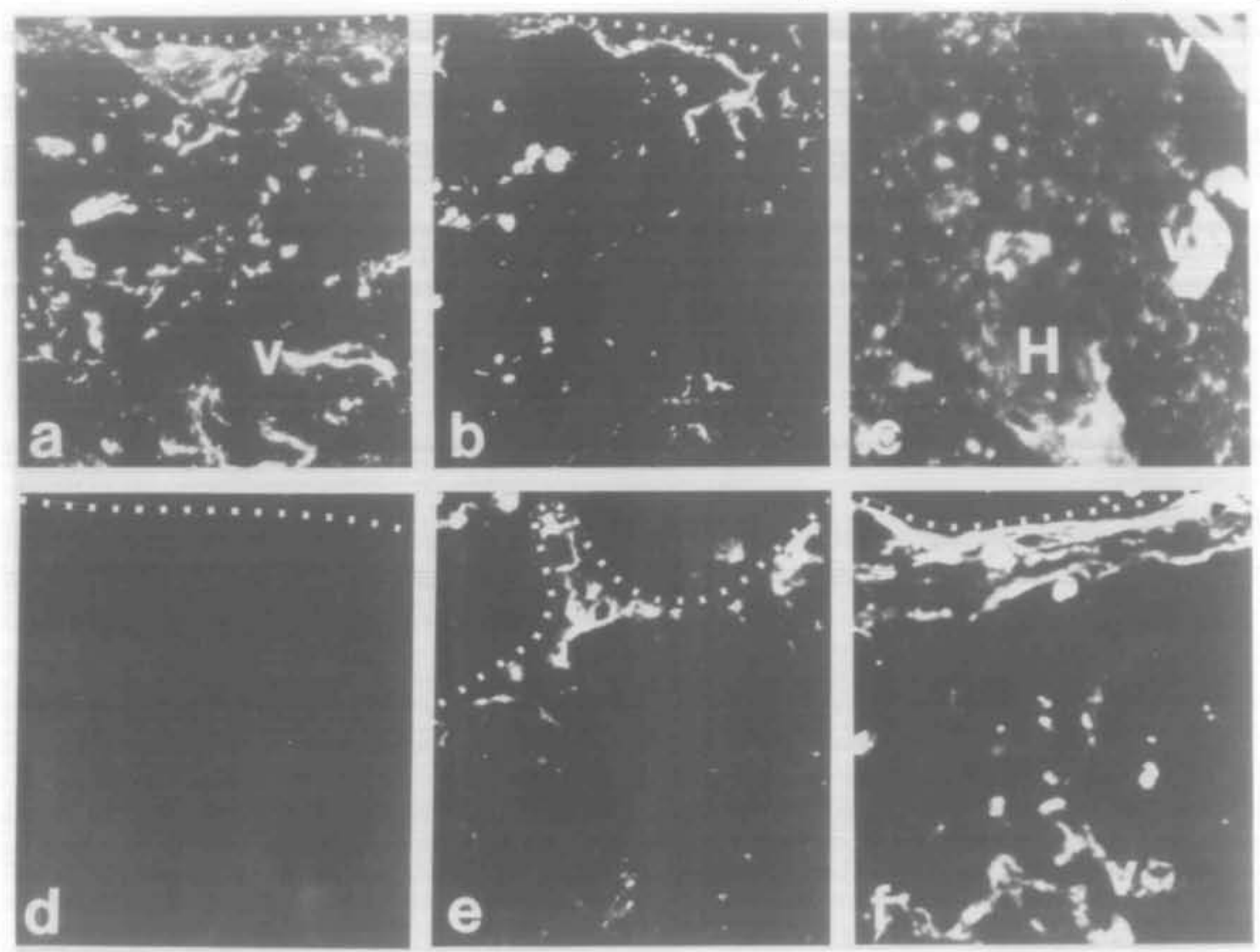

Fig. 9. Ontogeny of CD44 ligands FN and HA during human fetal thymic development. Panels (a)-(c) show reactivity of anti-FN antibody FN15. Panel (a) shows left thymus from 8.2 week fetus no. 58 . Panel (b) shows right thymus from 8.2 week fetal thymus no. 58 Panel (c) shows post-natal thymus no. 112. Panels (a) and (b) show that anti-FN antibody reacted with thymic capsule, vessels and fibrous tissue at the time of colonization with stem cells; anti-FN antibody also reacted with thymıc vessels and HB in post-natal thymus (panel c). Panels (d)$(f)$ show that HABP conjugated with biotin did not react with fetal thymus (no 58 ) at 8.2 weeks of gestation (panel $d$ ) while it did react with thymus in panel (e) (no. 57) from 16 weeks of gestation and with normal post-natal thymus (no. 112) in panel (f). HAPB-biotin reacted with thymic fibroblasts in the thymic capsule and with vessels (All panels $\times 400$.)

with retinoic acid (RA), which has been shown to induce differentiation in a variety of epithelial cell types $(32,33)$. RA $(1 \mu \mathrm{M}$ for $96 \mathrm{~h})$, associated with the withdrawal of standard TE media growth factors (epidermal growth factor and insulin), induced differentiation in $29 \pm 5 \%(N=3)$ of cells as determined by morphological change (Fig. 7) and reactivity with mAb TE19 or STE1. In RA-treated cultures, $20 \pm 7 \%$ of TE cells were reactive with $\mathrm{mAb} 11.24$. As before, reactivity of mAb 11.24 was highest on large TE cells as determined by analysis of fluorescence versus forward scatter. These data provide additional confirmation of the notion that CD $44 v 9$ expression on human TE cells was induced upon terminal differentiation.

\section{Detection of CD44 TE and thymocyte proteins by immuno- blot analysis}

To further analyze the isoforms of CD44 expressed by thymocytes and TE cells, soluble extracts of cell surface proteins from freshly isolated thymocytes, undifferentiated TE cells and well-differentiated TE cells were separated by polyacrylamide gel electrophoresis, immobilized on nitrocellulose membranes and CD44 proteins detected by immunoblot analysis using indirect immunoperoxidase staining. As shown in Fig. 8(B), mAb A3D8 (to all forms of CD44) detected predominantly $85 \mathrm{kDa}$ proteins in both thymocytes and TE cells from cultures that were not well differentiated. Also detected in undifferentiated TE cells, albeit at a low level, were at least four $(\sim 115,150,180$ and $>220 \mathrm{kDa})$ high molecular weight isoforms of CD44 (Fig. $8 \mathrm{C}$ ). All four of these high molecular weight isoforms of $\mathrm{CD} 44$ reacted with mAb to CD44v9 (not shown). While poorly differentiated TE cells expressed high levels of the $85 \mathrm{kDa}$ CD $44 \mathrm{~S}$ isoform of CD44, well differentiated TE cells (from the culture shown in Fig. 4B) expressed lower amounts of the $85 \mathrm{kDa}$ form of CD44 (Fig. 8D). Expression of the 150, 180 and $>220 \mathrm{kDa}$ high molecular weight variant isoforms of CD44 increased with differentiation while expression of the $115 \mathrm{kDa}$ variant isoform decreased (Fig. 8D).

\section{Ontogeny of CD44 ligands $H A$ and $F N$ during human fetal} thymic development

Finally, to begin to understand the relevance of location and timing of expression of CD44 isoforms in human thymus, we studied the ontogeny of expression of two CD44 ligands, HA 
(34-37) and FN (38), in fetal thymus. At the time of first entry of hematopoietic stem cells into the human thymic epithelial rudiment, the thymic capsule vessels and scattered thymic stromal cells expressed FN (Fig. 9a and b). In 13 (no. 56) and 16 (no. 57) week fetal thymuses, anti-FN mAb FN15 reacted with fibrous septae and vessels (not shown). In postnatal thymus containing $\mathrm{HB}$, fibrous septae, vessels and $\mathrm{HB}$ expressed FN (Fig. 9C). In contrast, in the recently colonized 8.2 week (no. 58) thymus and in the 13 week thymus, no thymic HA was detected (Fig. 9d), although HABP-biotin bound well to 8.2 week skin (not shown). However, at 16 weeks (no. 57) (Fig. 9e) and post-natally (no. 112) (Fig. 9f), HABP-biotin bound well to thymic capsule, interlobular septae and to vessels in 16 week thymus (no. 57) (Fig. 9e) and also. to HB of post-natal thymus (no. 112) (Fig. 9f), in a distribution similar to $\mathrm{FN}$. Thus, FN was expressed throughout thymic ontogeny beginning at 8.2 weeks, while thymic HA expression was acquired around 16 weeks of gestational age.

\section{Discussion}

In this study, we have found that CD44 mAbs against all CD44 isoforms reacted with thymic fibroblasts, thymocytes and TE cells from the time of first colonization of the thymus by stem cells, whereas mAbs against CD44 isoforms containing $v 4, v 6$ or $v 9$ inserts reacted only with terminally differentiated TE cells in HB beginning at 16-19 weeks of gestation Using mAb 11.24 against CD44v9, biochemical studies and flow cytometry in vitro on undifferentiated and differentiated TE cells confirmed the acquisition of CD44V9 expression with TE cell terminal differentıation. Finally, we found that expression of two CD44 ligands, HA and FN, differed in gestational age of expression, with FN present at the time of thymic colonization, while HA expression was acquired at 16 weeks.

The pattern of expression of CD44 isoforms and CD44 ligands in thymus was, in part, surprising. While nearly all PBL could be induced upon activation by phorbol esters to express variant isoforms of CD44 $(15,16)$, the majority of thymocytes could not. This observation is consistent with the notion that thymocytes are not yet fully functional and require additional maturation events either in the thymus prior to emigration from the thymus or in the periphery after emigration from the thymus (reviewed in 39). Since fibroblasts in most tissues do not express variant isoforms of CD44 (16; D. D. Patel et al., unpublished observations), it is not surprising that thymic fibroblasts do not express CD44v detectable by mAbs. While most eptthelial cells express both CD44S and CD44v isoforms $(16,40)$, undifferentiated TE cells express predominantly CD44S and differentiated TE cells express predominantly CD44v. Thus, induction of CD44v expression is a marker of terminally differentiating (squamous-shaped) medullary TE cells in and around thymic HB.

The up-regulation of CD44v9, v4 and v10 expression with TE cell differentiation and down-regulation of CD44S suggests that the expression of CD44 isoforms is developmentally regulated in TE cells. This change in the pattern of CD44 isoform expression during TE differentiation may be due to a variety of processes including alternative promoter use, posttranscriptional processing, message stability and post-trans- lational modification. The most likely event is a change in the mRNA splicing machinery, either by the acquisition of a prosplicing factor or the loss of an inhibitor, such that inclusion of variant exons is favored over exclusion. For example, differentiation has been shown to induce alternative splicing of the 4.1 membrane skeletal RNA in erythroid cells (41), the microtubule-associated tau gene RNA in neuroblastoma cells (42) and FN RNA during chondrogenesis (43). To fully evaluate this possıbility, future studies examıning the stability of CD44 mRNAs and proteins and the splicing patterns of CD44 RNAs will be of interest.

CD44 has been implicated in the homing of bone marrowderived precursor $T$ cells to the murine thymus. Not only is CD44 expressed on murine pro-thymocytes capable of homing to and re-populating the thymus (44), antibodies to CD44 inhibited the homing of pro-thymocytes in vivo to the murine thymus $(45,46)$, although this may have been due to antibody coated cells that were removed from the circulation by phagocytosis in the liver (1) In humans, CD44 isoforms are also expressed on thymic precursors (47) and antibodies to CD44 inhibited the binding of lymphocytes to high endothelial venules in lymph nodes $(48,49)$.

$H A$ is a glycosaminoglycan polymer with a molecular weight of up to several million daltons that is a ligand for CD44 (3437). While a varıety of lymphoid cells can be induced to bind $\mathrm{HA}$ in vitro (reviewed in 1), the existence of a true physiologic role for CD44-HA interactions in T cell development is controversial Our data that HA is not expressed at the time of initial colonization of the human thymus with thymocyte precursors (8.2 weeks of fetal gestation) suggests that CD44-HA interactions are not necessary for the migration of early thymic precursors to or within the thymus. Since HA is detected on thymic septae and vessels at later stages of thymic development when the first wave of thymocytes has had time to mature, it is possible that CD44-HA interactions may play a role in thymocyte emigration from thymus. Furthermore, as $H A$ is expressed on fibrous septae, CD44-HA interactions may serve to anchor stromal cells to the thymic extracellular matrix (ECM). Transfection of a CD44- B cell line with CD44S but not with CD44v8-10 conferred the ability to bind to lymph node HEV in an HA-dependent manner (37). In addition, Jurkat $T$ cells transfected with $C D 44 S$ but not those transfected with CD44v8-10 could be induced by phorbol myristate acetate treatment to bind $\mathrm{HA}(19)$, indicating that in the phorbol myristate acetate-Induced state CD44S, but not CD44v8-10, can bind HA. However, we have demonstrated induction of CD44v8-10 HA binding by mAb ligation of CD44v8-10 (19). We and others have noted that the pattern of CD44v expression differs between simple and stratified epithelia, in that high levels of CD44v4 and CD44v6 are expressed on stratified but not on simple epithelia $(16,40)$. Further, this pattern of expression is that expected of a molecule of stratified epithelia that mediates intracellular and cell-ECM but not cell-basement membrane interactions (40). This pattern is similar to another developmentally regulated ECM binding cell surface proteoglycan, syndecan, that has two forms that vary between simple and stratified epithelia $(50,51)$.

A second ligand for CD44, FN (38), may be important for both pro-thymocyte homing to thymus and for $T$ cell differentiation. FN consists of a family of very large $(\sim 500 \mathrm{kDa})$ 
glycoproteins that have clearly been shown in mice to mediate the binding of immature thymocytes to thymic stromal cells and to mediate thymocyte differentiation (52). Although these effects were mediated primarily by the RGD sequence that binds to integrins VLA-3 (CD49c/CD29), VLA-4 (CD49d/CD29) and VLA-5 (CD49e/CD29) (52,53), CD44-FN interactions may also play a role in these events. The chondroitin sulfated form of purified lymphocyte CD44 binds the C-terminal heparin binding domain of FN (38). However, it has been difficult to isolate CD44-FN interactions in cell bınding assays $(1,38)$, likely because of the predominance of integrin-FN interactions. Our data that $F N$ is expressed on thymic vessels from the time of initial colonization of the thymus with prothymocytes whereas HA is not detectable at this gestational age suggests that FN-FN receptor (CD44 or VLAs) interactions rather than CD44-HA interactions may be important for early thymic development.

\section{Acknowledgements}

The authors wish to thank Drs Hua-Xin Liao and Marc Levesque for helpful discussions, and Ms Kim McClammy for secretarıal assistance. This work was supported by SCOR grants AR39162 and CA28936. B F H. Is a Carter-Wallace Fellow for AIDS Research. L. P H is VFW Fellow for Cancer Research

\section{Abbrevlations}

$\begin{array}{ll}\alpha M M & \alpha \text {-D-mannopyranoside } \\ \text { CD44S } & \begin{array}{l}\text { standard form of CD44 contaıning exons 1-5, 15-17 } \\ \text { and } 19 \text { of the human CD44 gene }\end{array} \\ \text { CD44v9 } & \begin{array}{l}\text { Isoforms of CD44 contaınıng variant exon } 9 \\ \text { Con A }\end{array} \\ \text { concanavalin A } \\ \text { ECM } & \text { extracellular matrix } \\ \text { FN } & \text { fibronectın } \\ \text { HA } & \text { hyaluronan } \\ \text { HABP } & \text { hyaluronic acid bınding protein } \\ \text { HB } & \text { Hassall's bodies } \\ \text { PBMC } & \text { peripheral blood mononuclear cells } \\ \text { PHA } & \text { phytohemagglutınin } \\ \text { RA } & \text { retinoic acid } \\ \text { TE } & \text { thymic epithelial }\end{array}$

\section{References}

1 Lesley, J., Hyman, R. and Kincade, P. W. 1993. CD44 and its interaction with extracellular matrix. Adv. Immunol 54.271.

2 Günthert, U. 1993. CD44: a multitude of isoforms with diverse functions. Curr. Top. Microbiol Immunol 184:47

3 Screaton, G. R., Bell, M. V., Jackson, D. G., Cornelis, F. B , Gerth, U. and Bell, J. I. 1992. Genomic structure of DNA encoding the tymphocyte homing receptor CD44 reveals at least 12 alternatively spliced exons. Proc Natl Acad. Sci. USA 89:12160.

4 Haynes, B. F., Telen, M. J., Hale, L. P. and Denning, S. M. 1989. CD44-a molecule involved in leukocyte adherence and T-cell activation. Immunol. Today 10:423.

5 Haynes, B. F., Liao, H.-X. and Patton, K. L. 1991. The transmembrane hyaluronate receptor (CD44): multiple functions, multiple forms. Cancer Cells 3:347.

6 Patel, D. D. and Haynes, B. F. 1993. Cell adhesion molecules involved in intrathymic T cell development. Semin. Immunol. 5:283.

7 Reber, S., Matzku, S., Gũnthert, U., Ponta, H., Herrlich, P. and Zoller, M. 1990. Retardation of metastatic tumor growth after immunization with metastasis-specific monoclonal antibodies. Int. J. Cancer 46:919.

8 Gônthert, U., Hofmann, M., Rudy, W., Reber, S., Zoller, M.,
Hausmann, I., Matzku, S., Wenzel, A., Ponta, H. and Herrlich, P. 1991. A new variant of glycoprotein CD44 confers metastatic potential to rat carcinoma cells. Cell 65:13.

9 Heider, K.-H., Hofmann, M., Horst, E., van den Berg, F., Ponta, H., Herrlich, P. and Pals, S. T. 1993. A human homologue of the rat metastasis-associated variant of CD44 is expressed in colorectal carcinomas and adenomatous polyps. J. Cell. Biol. 120:227.

10 Rudy, W., Hofmann, M. Schwartz-Albiez, R., Zoller, M., Heider, K. H., Ponta, H. and Herrlich, P. 1993. Two major CD44 proteins expressed on a metastatic rat tumor cell line are derived from different splice variants. each one individually suffices to confer metastatic behavior. Cancer Res. 53:1262.

11 Seiter, S, Arch, R., Reber, S., Komitowski, D., Hofmann, M., Ponta, H., Herrlich, P., Matzku, S. and Zoller, M. 1993. Prevention of tumor metastasis formation by anti-variant CD44. J. Exp. Med 177:443.

12 Tanabe, K K., Ellis, L M. and Saya, H. 1993. Expression of CD44R1 adhesion molecule in colon carcinomas and metastases Lancet 341.725.

13 Denning. S. M., Kurtzberg. J., Leslie, D. S. and Haynes, B. F. 1989 Human postnatal $\mathrm{CD}^{-}, \mathrm{CD} 8^{-}, \mathrm{CD} 3^{-}$, thymic T cell precursors differentiate invitro into $\mathrm{T}$ cell receptor $\delta$-bearing cells. $J$. Immunol. 142:2988.

14 Terstappen, L. W., Huang, S. and Picker, L. J. 1992. Flow cytometric assessment of human T-cell differentiation in thymus and bone marrow. Blood 79:666

15 Arch, R. Wirth, K. Hofmann, M., Ponta, H., Matzku, S., Herrlich, P. and Zoller, M. 1992 Participation in normal immune responses of a metastasıs-inducing splice variant of CD44. Science 257:682.

16 Mackay, C. R., Terpe, H.-J., Stauder, R., Marston, W. L , Stark, H and Günthert, U. 1994 Expression and modulation of CD44 variant isoforms in humans. J. Cell. Biol. 124.71.

17 Telen, M. J., Eisenbarth, G S. and Haynes, B. F. 1983. Human erythrocyte antigens: regulation of expression of a novel erythrocyte surface antigen by the inhibitor Lutheran In(Lu) gene. J. Clin. Invest. $71: 1878$

18 Haynes, B. F., Harden, E A., Telen, M. J., Hemler, M. E., Strominger, J. L., Palker, T. P., Scearce, R. M and Eisenbarth, G. S. 1983 Differentiation of human T lymphocytes. I. Acquisition of a novel cell surface proteln ( 880 ) during normal intrathymic $T$ cell maturation. J. Immunol. 131:1195.

19 Liao, H.-X., Levesque, M. C., Patton, K, Bergamo, B., Jones, D., Moody, M. A., Telen, M. J. and Haynes, B. F 1993. Regulation of human $\mathrm{CD} 44 \mathrm{H}$ and $\mathrm{CD} 44 \mathrm{E}$ isoform binding to hyaluronan by phorbol myristate acetate and anti-CD44 monoclonal and polyclonal antibodies. J. Immunol. 151:6490.

20 Woodcock-Mitchell, J., Eicher, R., Nelson, W. G. and Sun, T. T. 1982. Immunolocalization of keratin polypeptides in human epidermis using monoclonal antibodies. J. Cell. Biol. 95:580.

21 Haynes, B. F., Scearce, R. M., Lobach, D. F. and Hensley, L. L. 1984. Phenotypic characterization and ontogeny of mesodermalderived and endocrine epithelial components of the human thymic microenvironment. J. Exp. Med. 159:1149.

22 Lobach, D. F., Scearce, R. M. and Haynes, B. F. 1985. The thymic microenvironment: phenotypic characterization of Hassal's bodies with the use of monoclonal antibodies. J. Immunol. 134:250.

23 Dimitriu-Bona, A., Burmester, G. R., Waters, S. J. and Winchester, R. J. 1983. Human mononuclear phagocyte differentiation antigens. I. Pattern of antigenic expression on the surface of human monocytes and macrophages defined by monoclonal antibodies. J. Immunol. 130:145

24 Lobach, D. F. and Haynes, B. F. 1987. Ontogeny of the human thymus during fetal development. J. Clin. Immunol. 7:81.

25 Singer, K H., Scearce, R. M., Tuck, D. T., Whichard, L. P., Denning, S. M. and Haynes, B. F. 1989. Rernoval of fibroblasts from human epithelial cell cultures with the use of a complement fixing monoclonal antibody reactive with human fibroblasts and monocytes/macrophages. J. Invest. Dermatol. 92:166.

26 Haynes, B. F., Hensley, L. L. and Jegasothy, B. V. 1982. Phenotypic characterization of skin-infiltrating $T$ cells in cutaneous T-cell lymphoma: comparison with benign cutaneous T-cell infiltrates. Blood 60:463. 
27 Green, S. J., Tarone, G and Underhill, C. B. 1988. Distribution of hyaluronate and hyaluronate receptors in the adult lung. J. Cell. Sci. $90: 145$.

28 Singer, $K$ H, Harden, E. A., Robertson, A. L., Lobach, D. F. and Haynes, B. F. 1985. In vitro growth and phenotypic characterization of mesodermally-derived and epithelial components of normal and abnormal human thymus. Human Immunol. 13:161.

29 Lobach, D. F., Itoh, T., Singer, K H. and Haynes, B F 1987. The thymic microenvironment. Characterization of in vitro differentiation of the IT26R21 rat thymic epithelial cell line. Differentiation 34:50.

30 Dennıng, S M., Tuck, D. T., Vollger, L. W., Springer, T. A., Singer, K. H. and Haynes, B. F. 1987. Monoclonal antibodies to CD2 and LFA-3 inhibit human thymic epithelial cell-dependent mature thymocyte activation J. Immunol. 139:2573.

31 Haynes, B F. 1990 Human thymic epithelium and $T$ cell development: current issues and future directions. Thymus 16:143.

32 Peehl, D. M., Wong, S. T. and Stamey, T. A, 1993. Vitamin A regulates proliferation and differentiation of human prostatic epithelial cells Prostate 23:69

$33 \mathrm{Chol}, \mathrm{Y}$. and Fuchs, E. 1990. TGF-beta and retinoic acid regulators of growth and modifiers of differentiation in human epidermal cells. Cell Regulation 1:791.

34 Culty, M., Miyake, K, Kincade, P. W., Sikorski, E., Butcher, E C and Underhill, C. B. 1990. The hyaluronate receptor is a member of the CD44 (H-CAM) family of cell surface glycoproteins. J. Cell. Bıol $111 \cdot 2765$

35 Lesiey, J., Schulte, R. and Hyman, R. 1990. Binding of hyaluronic acid to lymphoid cell lines is inhibited by monoclonal antibodies agaınst Pgp-1 Exp. Cell. Res. 187.224.

36 Miyake, K., Underhill, C. B., Lesley, J and Kincade, P. W. 1990. Hyaluronate can function as a cell adhesion molecule and CD44 participates in hyaluronate recognition J Exp. Med. 172.69

37 Stamenkovic, I, Aruffo, A. Amıof, M. and Seed, B. 1991. The hematopoietic and epithelial forms of $\mathrm{CD} 44$ are distınct polypeptides with different adhesion potentials for hyaluronatebearing cells. EMBO J. 10:343.

38 Jalkanen, S and Jalkanen, M. 1992. Lymphocyte CD44 binds the $\mathrm{COOH}$-terminal heparin-binding domain of fibronectin. J. Cell. Biol. 116:817.

39 Haynes, B F. and Denning, S. M. 1993. Lymphopoiesıs. In Stamatoyannopoulas, G., Neinhuis, A., Majerus, P. and Varmus, H., eds, The Molecular Basis of Blood Diseases, 2nd edn, p. 425. W. B. Saunders, Philadelphia.

40 Hale, L P., Patel, D D., Mackay, C. R. and Haynes, B. F. 1995. Expression of variant isoforms of CD44 differs between secretory and stratified epithelia. In Schlossman, S. et al., eds, Leukocyte
Typing $V$, Oxford University Press, Oxford

41 Chasis, J. A., Coulombel, L., Conboy, J McGee, S., Andrews, K. Kan, Y. W. and Mohandas, N. 1993. Differentiation-associated switches in protein 4.1 expression. Synthesis of multiple structural isoforms during normal human erythropolesis $J$ Clin. Invest 91:329.

42 Montejo de Garcini, E., Corrochano, L., Wischık, C. M., Diaz Nıdo, J., Correas, I. and Avila, J. 1992. Differentiation of neuroblastoma cells correlates with an altered splicing pattern of tau RNA. FEBS Lett. 299:10.

43 Bennett, V. D., Pallante, K M. and Adams, S L 1991 The splicing pattern of fibronectin in mRNA changes during chondrogenesis resulting in an unusual form of the mRNA in cartilage. $J$ Cell. Biol. 266:5918

44 Trowbridge, I. S., Lesley, J., Schulte, R., Hyman, R. and Trotter, J. 1982. Bıchemical characterizatıon and cellular distribution of a polymorphic, murine cell-surface glycoprotein expression on tymphoid tissues. Immunogenetics 15.299 .

45 Lesley, J, Hyman, R. and Schulte, R 1985. Evidence that the Pgp-1 glycoprotein is expressed on thymus-homıng progenitor cells of the thymus. Cell Immunol 91:397.

46 O'Neill, H. C. 1989. Antibody which defines a subset of bone marrow cells that can migrate to the thymus Immunology 68:59.

47 de la Hera, A. Acevedo, A., Marston, W. and Sanchez-Madrid F. 1989. Function of CD44 (Pgp-1) homing receptor in human $T$ cell precursors. Int. Immunot $\mathbf{1 . 5 9 8}$

48 Jalkanen, S., Jalkanen, M., Bargatze, R., Tammı, M. and Butcher, E. C. 1988. Biochemical properties of glycoprotens involved in lymphocyte recognition of high endothelial venules in man. $J$. immunol. 141:1615.

49 Jalkanen, S., Bargatze, R F, de los Toyos, J. and Butcher, E. C. 1987. Lymphocyte recognition of high endothelium: antibodies to distinct epitopes of an 85-95kd glycoprotein antigen differentially inhibit lymphocyte binding to lymph node, mucosal, or synovial endothelıal cells. J. Cell. Biol. 105.983.

50 Saunders, S. and Bernfield, M. 1988. Cell surface proteoglycan bınds mouse mammary epithelial cells to fibronectin and behaves as a receptor for interstitial matrıx. J. Cell. Biol. 106:423.

51 Sanderson, R. D. and Bernfield, M. 1988. Molecular polymorphism of a cell surface proteoglycan distinct structures on simple and stratfied epithelia. Proc. Natl Acad Sci. USA 85:9562.

52 Utsumi, K., Sawada, M. Narumiya, S., Nagamine, J., Sakata, T., Iwagami, S., Kita, Y., Teraoka, H., Hirano, H., Ogata, M., Hamaoka, $T$ and Fujiwara, $H$. 1991. Adhesion of immature thymocytes to thymic stromal cells through fibronectin molecules and its significance for the induction of thymocyte differentiation Proc. Natl Acad. Sci. USA 88.5685.

53 Hemler, M. E 1990. VLA proteins in the integrin family: structures, functions, and their role on leukocytes. Annu. Rev. Immunol. 8.365. 